\title{
Factors affecting expression of estrus measured by activity monitors and conception risk of lactating dairy cows
}

\author{
A. M. L. Madureira, ${ }^{*} \dagger$ B. F. Silper, ${ }^{*}$ T. A. Burnett, ${ }^{*}$ L. Polsky, ${ }^{*}$ L. H. Cruppe, $\ddagger$ D. M. Veira, ${ }^{*}$ \\ J. L. M. Vasconcelos, $†$ and R. L. A. Cerri*1 \\ *Faculty of Land and Food Systems, University of British Columbia, Vancouver V6T 1Z4, Canada \\ †Department of Animal Production, São Paulo State University, Botucatu, Brazil 18168-000 \\ ‡Department of Animal Sciences, The Ohio State University, Columbus 43210
}

\section{ABSTRACT}

The objective of this study was to determine riskfactors affecting increase in physical activity during estrus and pregnancy per artificial insemination $(\mathrm{P} /$ AI) in lactating dairy cows. Cows were monitored continuously by 2 automated activity monitors [a collarmounted accelerometer (HT; Heatime, SCR Engineers, Netanya, Israel) and a leg-mounted pedometer (BO; Boumatic Heat-seeker-TX, Boumatic Dairy Equipment, Madison, WI)]. When an increase in activity was detected, body condition score (BCS) and blood samples were collected, ovaries were scanned by ultrasonography, and, if the cow was eligible for breeding, artificial insemination was performed. Milk production and health-related data were recorded throughout the experimental period. Pregnancy diagnosis was performed at $42 \pm 7 \mathrm{~d}$ of gestation. Data were analyzed using Pearson correlation, ANOVA, and logistic regression. A total of 1,099 true events of estrus from 318 lactating Holstein cows were recorded, averaging $3.46 \pm 1.1$ events per cow. Positive predictive value for estrus episodes detected by the HT and BO systems were 89.6 and $85.5 \%$, respectively. Mean peak activity at estrus (PA) recorded by the HT system was $71.6 \pm$ 20.7 index-value, and $334.3 \pm 155.7 \%$ relative increase by the BO system. Compared with primiparous, multiparous cows expressed estrus with lower PA (69.3 \pm 0.8 vs. $75.9 \pm 1.1$ index for HT; $323.9 \pm 6.0$ vs. 354.8 $\pm 8.48 \%$ for BO) and shorter duration (DU; $10.7 \pm 0.2$ vs. $12.0 \pm 0.3 \mathrm{~h}$ ); DU was measured by HT only. Lower BCS was associated with decreased PA measured by both systems, estrus DU, and P/AI. Peak activity was weakly correlated with milk production on the day of artificial insemination $(\mathrm{r}=-0.20)$; however, when categorized into quartiles, the highest-yield cows had

Received April 6, 2015.

Accepted June 17, 2015

${ }^{1}$ Corresponding author: ronaldo.cerri@ubc.ca lower PA and DU. Follicle diameter was not correlated with PA or DU, but cows with greater concentrations of estradiol had higher PA. Cows with greater PA in both systems had greater $\mathrm{P} / \mathrm{AI}$ than those with lower PA (36.5 vs. $24.6 \%$ for HT, 33.5 vs. $21.4 \%$ for BO). In conclusion, measurements of estrus events captured by automated activity monitors are correlated with BCS, parity, and secondary behavior signs related to estrus. Surprisingly, estrus intensity and duration were only weakly correlated with milk production, preovulatory follicle diameter, and concentrations of estradiol at estrus. Cows that had measurements of high-intensity estrus were significantly more fertile than low-intensity estrus.

Key words: automated activity monitor, pregnancy per artificial insemination, milk production, estrus expression

\section{INTRODUCTION}

Some studies have indicated the negative effect of milk production on standing to be mounted and total time standing (López et al., 2004; Rivera et al., 2010), whereas others do not report such an effect (Lyimo et al., 2000; Van Eerdenburg et al., 2002). The use of automated activity monitor (AAM) technology to assist estrus detection may be used to retrieve useful data regarding estrous behavior parameters. The effects of the animal's metabolic status and ovarian dynamics on pregnancy per AI (P/AI) has been extensively studied when using timed AI programs, but limited data are available of such effects on estrus behavior as measured by current AAM technologies and consequent fertility from cows inseminated upon natural or induced estrus.

High-yielding dairy cows have an elevated metabolic rate, which increases liver blood flow and metabolism of steroid hormones (Sangsritavong et al., 2002; Vasconcelos et al., 2003). As a result, these cows experience decreased circulating estradiol concentrations that could be a possible cause of shorter and less intense expres- 
sion of estrus (López et al., 2004; Rivera et al., 2010; Roelofs et al., 2010). Historically, mounting behavior and standing to be mounted have been considered the clearest indicator of an estrus event, but its expression tends to decrease with greater milk production (López et al., 2004; Rivera et al., 2010). The need for more efficient and reliable technologies for estrus detection has led to the development of activity monitors that rely on the relative increase in physical activity of the animal (Jónsson et al., 2011) instead of mounting activity and other secondary signs. The technology currently used on dairy farms varies because different products measure different features of physical activity (e.g., accelerometers, pedometers, neck-mounted, leg mounted, ear tags). A recent study conducted in Denmark (Lovendahl and Chagunda, 2010) using AAM showed a $74.6 \%$ estrous detection rate and $1.3 \%$ daily error rate, demonstrating the advantages of this technology compared with visual detection. López-Gatius et al. (2005) reported that the 2 main factors affecting activity increases were lactation number and milk production, and that a small but positive correlation exists between intensity of activity and P/AI. Moreover, Holman et al. (2011) reported that milk production affects the overall sensitivity of activity monitors, but others have reported no correlation between milk yield and expression of estrus behavior detected by the AAM (Lyimo et al., 2000; Van Eerdenburg et al., 2002).

Few of the previous studies measured detailed reproductive physiological parameters associated with natural estrus behaviors, and the subsequent intensity and duration of activity detected by AAM. The effects of preovulatory follicle diameter, circulating estradiol concentrations, and even a better understanding of the effect of estrus intensity and duration on $\mathrm{P} / \mathrm{AI}$ are still unclear. In addition, the technology used has evolved, sensors have become more sensitive, and different algorithms are used to transform the raw data, which can interfere with interpretation and correlation with phenotypical measurements.

The objectives of our study were to identify risk factors associated with measurements of estrus expression and P/AI. The effects of parity, BCS, milk production, stage of lactation, secondary signs of estrus, preovulatory follicle diameter, and concentration of estradiol in plasma at the moment of increased activity on the intensity and duration of estrus detected by AAM systems were analyzed. In addition, risk factors associated with $\mathrm{P} / \mathrm{AI}$, particularly those related to estrus outcomes (intensity and duration), were assessed. Two AAM systems commonly used on dairy operations in North America were used to correlate and compare the estrus outcomes with production, reproduction, and other cow-related measurements.

\section{MATERIALS AND METHODS}

This experiment was conducted between April 2012 and April 2013 at the University of British Columbia's Dairy Education and Research Centre in Agassiz, Canada $\left(49^{\circ} 13^{\prime} 59^{\prime \prime} \mathrm{N}, 121^{\circ} 46^{\prime} 01^{\prime \prime} \mathrm{W}\right)$. The local Institutional Animal Care Committee following the requirements of the Canadian Animal Care Council (2009) approved all experimental procedures.

\section{Animals, Housing, and Management}

Lactating Holstein cows $(\mathrm{n}=346)$ were enrolled onto the study during the first week postpartum. The experimental herd had an average 305-d mature equivalent milk yield of $12,236 \pm 2,219 \mathrm{~kg} /$ cow in 2013 .

Cows were housed in sand-bedded freestalls $(2.4 \mathrm{~m}$ long $\times 1.18 \mathrm{~m}$ wide $\times 0.40 \mathrm{~m}$ deep; at least 1 stall $/ \mathrm{cow})$ with concrete flooring. Milking was performed twice daily at 0500 and $1500 \mathrm{~h}$. Cows were fed a TMR twice daily at approximately 0700 and $1600 \mathrm{~h}$ (pushed up 3 times/d). The TMR was formulated to meet or exceed the requirements of a $620-\mathrm{kg}$ Holstein cow producing 40 $\mathrm{kg} / \mathrm{d}$ of $3.5 \% \mathrm{FCM}$ (NRC, 2001). Water and TMR were available for ad libitum intake.

\section{$A A M$}

Cows were monitored continuously by 2 AAM: (1) a neck-mounted accelerometer (HT; Heatime, SCR Engineers, Netanya, Israel) and (2) a leg-mounted pedometer (BO; Boumatic Heat-seeker-TX, Boumatic Dairy Equipment Co., Madison, WI). The HT was fitted to the upper left side at the cranial portion of the cow's neck at $7 \pm 3$ DIM and removed if a positive pregnancy diagnosis was detected at $47 \pm 3 \mathrm{~d}$ post-AI. The BO sensor was attached to the right-front limb above the distal expansion of the metacarpal bone of each cow on the day of their first calving and remained with the animals throughout their entire time within the herd.

Activity data from HT was recorded in real time every $2 \mathrm{~h}$ by a wireless receiver box, which transmitted the data to a receiving unit connected to the farm manager's computer. The raw activity data from each cow was computed into an index value that is closely associated with the SD of the PA (calculated using the raw PA value and baseline values of the previous $14 \mathrm{~d}$. Index values ranged from 0 to 100 and the threshold for an episode of high activity was set at 35 . The time of the onset and end of high activity, peak of activity, and activity duration were obtained from the consecutive timeframe the animal's activity was above the threshold. The peak of physical activity index (PA) was defined as the maximum index value at an estrus episode. 
The duration of each episode (DU) was considered as the interval from the start hour of the first 2-h block above the activity threshold to the hour after the last 2-h block above the activity threshold. An Excel macro (Excel; Microsoft Corporation, Redmond, WA) was used to identify estrus events from the exported HT backup files. The macro-edited file contained information of cow number, collar tag number, date and hour (start hour of the first 2-h block), DU of estrus, and index value of PA for each estrus episode. Data from HT was also used to calculate the standard deviation of estrus activity from the average raw of the previous $14 \mathrm{~d}$.

Data from BO system was used for comparison purposes; only PA was measured. The pedometer contains a mercury switch that registers and records movements when its position has changed. The data were recorded in 2 -h increments and was retrieved twice daily by an electronic scanner attached to an archway at the milking parlor's entrance. An estrus event was recorded when activity exceeded $80 \%$ of the cow's baseline activity. The PA for the BO system was described as the relative percent increase in activity from the cow's baseline activity levels.

\section{Blood Sampling, BCS, and Analysis of Estradiol}

Blood samples $(7 \mathrm{~mL})$ were harvested from the median coccygeal vein or artery utilizing Vacutainer tubes (Becton Dickinson, Rutherford, NJ) with $\mathrm{K}_{2}$ EDTA. Blood samples were collected immediately following an estrus alert (increase in physical activity that exceeded the threshold) from the HT system. The HT system updated the information in real-time every $2 \mathrm{~h}$, which allowed for blood sample collection at the earliest possible time after initiation of estrus. All samples were placed immediately on ice, transported to the laboratory, and centrifuged at $2,000 \times \mathrm{g}$ for $15 \mathrm{~min}$ at $5^{\circ} \mathrm{C}$ for separation of plasma. Plasma samples were then stored at $-80^{\circ} \mathrm{C}$ to be analyzed for estradiol concentration. Plasma concentrations of estradiol were determined using a double-antibody I-125-based assay described by Burke et al. (2003), with modifications. Average intraassay coefficient of variation was $4.2 \%$, and interassay coefficient of variation (18 assays) for pooled plasma samples containing $2.7,5.8$, and $12.3 \mathrm{pg} / \mathrm{mL}$ of estradiol were $6.3,5.2$, and $4.1 \%$, respectively. The average sensitivity of the estradiol assay was $1.1 \mathrm{pg} / \mathrm{mL}$. All cows had BCS (Edmonson et al., 1989) recorded each time an estrus episode was detected by the AAM. Secondary estrus signs were documented at the time of increased activity and through examination of the reproductive tract (signs of repeated mounting activity, clear vaginal mucus, and uterine tonus).

\section{Ultrasonography, Al, and Pregnancy Diagnosis}

Cows had their ovaries examined by ultrasound (Aloka SSD-500, Aloka Co. Ltd., Wallingford, CT) using a $7.5-\mathrm{MHz}$ linear rectal transducer, immediately following an episode of high activity detected by the AAM. The presence and diameter of the largest follicles were measured and recorded. The following reproductive management protocol was used throughout the trial: cows were AI upon estrus detected by the activity monitor using the a.m./p.m. rule. Cows were bred twice a day, at roughly 0700 and $1900 \mathrm{~h}$. If the activity alert occurred at $0200 \mathrm{~h}$, the cow would only be bred at $1900 \mathrm{~h}$. If the alert came on at $1600 \mathrm{~h}$, the breeding would occur at $0700 \mathrm{~h}$ of the next day. If no further estrus activity was recorded, cows were examined with an ultrasound at $42 \pm 3 \mathrm{~d}$ post-AI for the detection of a viable embryo.

\section{Statistical Analyses}

This experiment was an observational cohort study. A total of 1,161 estrus events were recorded, with 3.5 \pm 1.1 events per animal. Means, standard deviations, distributions, and normality tests were obtained using Univariate procedure in SAS software version 9.4 (SAS Institute Inc., Cary, NC). Normality was visually assessed and confirmed by the Kolmogorov-Smirnov method. Class variables used for analyses were described below. Parity was divided as cows in first lactation or second lactation and higher (primiparous vs. multiparous). The BCS classes were low ( $\mathrm{BCS} \leq 2.5)$, moderate $(\mathrm{BCS} \geq 2.75$ and $\leq 3.0)$, and high $(\mathrm{BCS} \geq 3.25)$. Lactation stage of the estrus episode was defined by DIM at the moment of the event: fresh $(\leq 45$ DIM), lactation (45 to $120 \mathrm{DIM}$ ), and late (121 to 250 DIM). Milk production was classified into quartiles as $\leq 31.3 \mathrm{~kg} / \mathrm{d}$ (first quartile), 31.4 to $38.8 \mathrm{~kg} / \mathrm{d}$ (second quartile), 38.9 to $45.1 \mathrm{~kg} / \mathrm{d}$ (third quartile), and $>45.1 \mathrm{~kg} / \mathrm{d}$ (fourth quartile). Expression of secondary signs of estrus (signs of repeated mounting activity, clear vaginal mucus, and uterine tonus) was classified as weak (1 secondary sign), normal (2 secondary signs), or strong (all 3 secondary signs). The PA of estrus episodes from the HT system was divided as low (35 to 89 index) and high (90 to 100 index), whereas for the BO system it was divided as low (80 to $321 \%$ relative increase) and high (321 to 999\% relative increase). Receiver operating characteristic analysis using MedCalc version 11.1.0.0 (MedCalc Software, Mariakerke, Belgium) was performed to determine the critical value of PA (index and relative increase) to optimize $\mathrm{P} / \mathrm{AI}$ based on sensitivity and specificity. The receiver operating characteristic curve analysis plots the sensitivity against the false positive 
fraction (1 - specificity) to detect the best combination of sensitivity and specificity for $\mathrm{P} / \mathrm{AI}$. The positive predictive value (PPV; true estrus events/total estrus events detected by the AAM system) of each system was calculated using total estrus episodes detected by both systems combined [true and false events; based on the presence of a preovulatory follicle larger than 10 $\mathrm{mm}$ in diameter and absence of an active corpus luteum (more than $20 \mathrm{~mm}$ in diameter)].

Correlations between PA and DU within and between systems were determined by Pearson correlation using the Corr procedure of SAS. Correlations were also calculated similarly for the relationship between physiological measurements (BCS, diameter of preovulatory follicle, and plasma estradiol concentration) and automated measurements (PA from HT and BO, DU from HT). Continuous data were analyzed by ANOVA using the MIXED procedure of SAS, with cow nested within estrus event as the random error. Only independent variables significantly different at the univariable level were included in the final model. Dichotomous outcome, such as P/AI, were evaluated by logistic regression using the Logistic procedure and frequency statistics were calculated using the Freq procedure of SAS. The model used in the logistical regression included the effects of parity, BCS, stage of lactation, PA and DU category, and interactions. A backward stepwise regression model was used (Allison, 1999). Variables were continuously removed from the model by the Wald statistic criterion if the significance was $P>0.15$. Differences with $P<$ 0.05 were considered significant and those between 0.05 $>P<0.10$ were designated as tendency.

\section{RESULTS}

\section{Animals and Number of Events}

A total of 1,161 events were detected. The HT system detected 1,041 episodes, whereas the BO system detected 993 estrus events; 948 events were detected by both systems. Analysis of PPV included all the detected events. The HT system had a PPV of $89.6 \%$ $(933 / 1,041)$, whereas the PPV of BO system was $85.5 \%$ (849/993).

Estrus events were considered true events after confirmation of a presence of a preovulatory follicle larger than $10 \mathrm{~mm}$ in diameter and absence of an active corpus luteum less than $20 \mathrm{~mm}$ in diameter measured by ultrasonography. Only true estrus events were used for the analyses regarding risk factors affecting PA and DU of estrus events. Among all detected events, 1,099 were true estrus events. From these 1,099 estrus events, 629 were followed by AI with subsequent pregnancy diagnosis. The average milk production was $38.6 \pm 9.0$ $\mathrm{kg} /$ cow per day. Cows had a mean lactation number of $2.6 \pm 1.8$ and were $99.4 \pm 60.2 \mathrm{DIM}$ at the time of data collection.

\section{Description of Estrus Events}

The mean PA recorded by HT system was $71.6 \pm$ 20.7 (index value). The HT index has no measurement unit as it translates the raw data from the system into a scale from 35 to 100 . The index is closely associated with the SD of the PA (calculated using the raw PA value and baseline values of the previous $14 \mathrm{~d}$ ) with an correlation coefficient of $0.54(P<0.01$; Figure $1 \mathrm{~A})$. The distribution of PA measured by HT was skewed to the left. The PA from BO system was $334.3 \pm 155.7 \%$ relative increase with a normal distribution pattern. The correlation coefficient between PA data of the 2 systems was $0.55(P<0.01$; Figure 1B). Mean estrus $\mathrm{DU}$ as measured by HT system was $11.2 \pm 5.3 \mathrm{~h}$. The PA and DU measured by HT system were positively correlated $(\mathrm{r}=0.82, P<0.01$; Figure $1 \mathrm{C})$. For $\mathrm{HT}$ measurements, estrus of high PA had longer DU (16.4 $\pm 0.3 \mathrm{~h}$ vs $9.8 \pm 0.1 \mathrm{~h} ; P<0.01)$ when compared with estrus of low PA.

\section{Factors Affecting PA and DU of Estrus Events: Animal Data}

Parity had a marked effect on estrus measurements as multiparous cows expressed estrus of lower PA $(P<$ $0.01)$ and shorter duration $(P<0.01)$ than primiparous cows, as shown in Table 1. The BCS of the cow at time of estrus affected PA in both $\mathrm{HT}$ and $\mathrm{BO}$ systems and DU $(P<0.01$; Table 1$)$, as cows with BCS $\leq 2.5$ showed less intense estrus measurements. Lactation stage did influence PA and DU of estrus events $(P<0.01$; Table $1)$. Cows that displayed secondary signs of estrus had greater PA measured by both systems and longer DU $(P<0.01$; Table 1$)$. These measurements progressively increased as more secondary signs were displayed concomitantly. Milk production was negatively correlated with PA $(\mathrm{r}=-0.20, P<0.01$; Figure 2$)$. Greater milk production was associated with lower PA and shorter DU of estrus (Table 1).

\section{Factors Affecting PA and DU of Estrus Events: Ovarian Data}

Preovulatory follicle diameter $(19.0 \pm 5.7 \mathrm{~mm})$ was weakly correlated with PA (HT: $\mathrm{r}=0.07, P=0.03$; BO: $\mathrm{r}=0.01, P=0.04$; Figure 3 ) or DU $(\mathrm{r}=0.06$, $P=0.08$ ) of estrus events. Data regarding preovulatory follicle and estradiol concentrations is shown in Table 2. Similarly, the diameter of the follicle did not 
A)
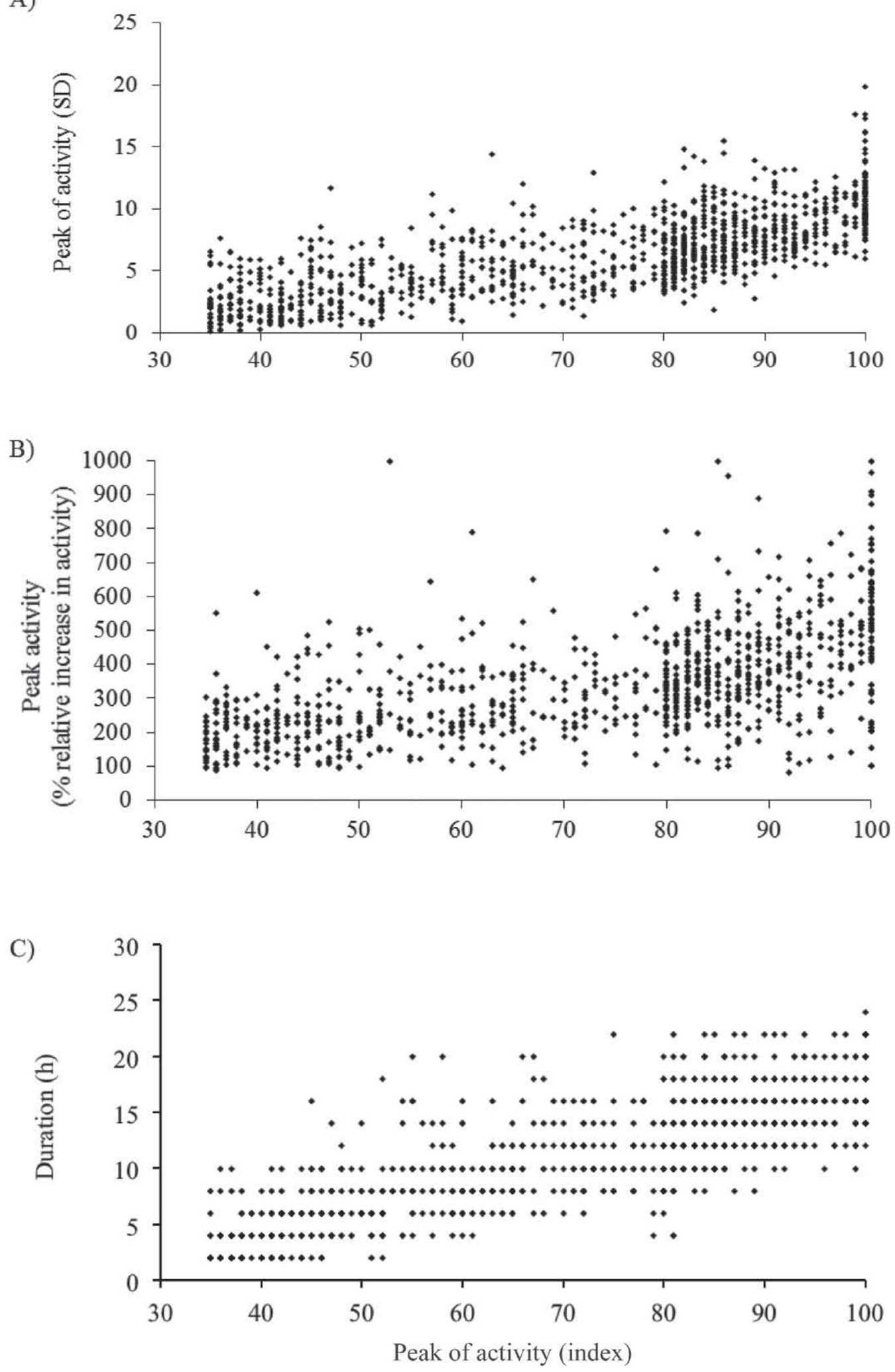

Figure 1. Correlations between peak of activity (index value; measured by a neck-mounted accelerometer; HT) and (A) estrus activity in standard deviations (calculated using the raw PA value and baseline values of the previous $14 \mathrm{~d}$ from $\mathrm{HT}$ data; $\mathrm{r}=0.54, P<0.01$ ); $(\mathrm{B})$ percent relative increase in activity at estrus measured by a leg-mounted pedometer $(\mathrm{r}=0.55, P<0.01)$; and $(\mathrm{C})$ duration (h) of activity above the threshold (35 index-value) measured by HT $(\mathrm{r}=0.82, P<0.01)$. 
Table 1. Means \pm SD for peak estrus activity (index and percent relative increase in activity), estrus duration, on index activity and pregnancy per AI according to BCS, parity, milk production, lactation stage, and secondary signs of estrus

\begin{tabular}{|c|c|c|c|c|}
\hline \multirow[b]{2}{*}{ Variable } & \multicolumn{2}{|c|}{ Peak activity } & \multirow[b]{2}{*}{$\begin{array}{l}\text { Duration } \\
(\mathrm{h})^{1}\end{array}$} & \multirow[b]{2}{*}{$\begin{array}{l}\text { Pregnancy } \\
\text { per AI }(\%)^{2}\end{array}$} \\
\hline & Index $^{3}$ & $\begin{array}{c}\text { Relative } \\
\text { increase }^{4}(\%)\end{array}$ & & \\
\hline \multicolumn{5}{|l|}{$\mathrm{BCS}$} \\
\hline Low $(\leq 2.5)$ & $65.2 \pm 1.5^{\mathrm{a}}$ & $294.7 \pm 11.3^{\mathrm{a}}$ & $9.6 \pm 0.4^{\mathrm{a}}$ & $16.8^{\mathrm{a}}(7 / 29)$ \\
\hline Medium (2.75 to 3.0$)$ & $73.8 \pm 0.8^{\mathrm{b}}$ & $345.7 \pm 6.0^{\mathrm{b}}$ & $11.4 \pm 0.5^{\mathrm{b}}$ & $28.6^{\mathrm{b}}(122 / 427)$ \\
\hline High $(\geq 3.25)$ & $71.9 \pm 1.9^{\mathrm{b}}$ & $339.2 \pm 14.9^{\mathrm{b}}$ & $11.6 \pm 0.2^{\mathrm{b}}$ & $39.7^{\mathrm{c}}(17 / 101)$ \\
\hline \multicolumn{5}{|l|}{ Parity } \\
\hline Primiparous & $75.9 \pm 1.1^{\mathrm{a}}$ & $354.8 \pm 8.4^{\mathrm{a}}$ & $12.0 \pm 0.3^{\mathrm{a}}$ & $27.3(59 / 216)$ \\
\hline Multiparous & $69.3 \pm 0.8^{\mathrm{b}}$ & $323.9 \pm 6.0^{\mathrm{b}}$ & $10.2 \pm 0.2^{\mathrm{b}}$ & $27.7(115 / 415)$ \\
\hline \multicolumn{5}{|l|}{ Secondary signs of estrus ${ }^{5}$} \\
\hline Weak & $66.6 \pm 1.0^{\mathrm{a}}$ & $308.3 \pm 7.7^{\mathrm{a}}$ & $10.1 \pm 0.3^{\mathrm{b}}$ & $28.6(47 / 191)$ \\
\hline Normal & $73.3 \pm 1.1^{\mathrm{b}}$ & $340.7 \pm 9.0^{\mathrm{b}}$ & $11.7 \pm 0.3^{\mathrm{a}}$ & $24.6(63 / 216)$ \\
\hline Strong & $76.8 \pm 1.2^{\mathrm{c}}$ & $362.9 \pm 8.9^{c}$ & $12.2 \pm 0.3^{\mathrm{a}}$ & $29.2(64 / 224)$ \\
\hline \multicolumn{5}{|l|}{ Milk production $(\mathrm{kg} / \mathrm{d})$} \\
\hline$\leq 31.3$ & $74.6 \pm 1.4^{\mathrm{a}}$ & $350.3 \pm 11.1^{\mathrm{a}}$ & $12.1 \pm 0.3^{\mathrm{a}}$ & $26.9(42 / 164)$ \\
\hline$\overline{31.4-38.8}$ & $71.6 \pm 1.4^{\mathrm{b}}$ & $322.4 \pm 11.2^{\mathrm{b}}$ & $11.6 \pm 0.3^{\mathrm{a}}$ & $29.0(51 / 176)$ \\
\hline $38.9-45.1$ & $68.5 \pm 1.5^{\mathrm{b}}$ & $312.8 \pm 11.3^{\mathrm{b}}$ & $10.3 \pm 0.3^{\mathrm{b}}$ & $25.3(40 / 158)$ \\
\hline$>45.0$ & $64.4 \pm 1.4^{\mathrm{b}}$ & $307.2 \pm 11.2^{\mathrm{b}}$ & $9.6 \pm 0.3^{\mathrm{b}}$ & $28.7(39 / 139)$ \\
\hline \multicolumn{5}{|l|}{ Lactation stage } \\
\hline Fresh $(\leq 45$ DIM $)$ & $67.9 \pm 1.7^{\mathrm{a}}$ & $308.8 \pm 12.8^{\mathrm{a}}$ & $9.8 \pm 0.4^{\mathrm{a}}$ & - \\
\hline Lactating (45-120 DIM) & $71.6 \pm 1.0^{\mathrm{b}}$ & $334.8 \pm 8.2^{\mathrm{b}}$ & $11.4 \pm 0.2^{\mathrm{b}}$ & $29.7(111 / 374)$ \\
\hline Late (121-250 DIM) & $69.8 \pm 1.3^{\mathrm{ab}}$ & $325.9 \pm 10.2^{\mathrm{b}}$ & $11.6 \pm 0.3^{\mathrm{b}}$ & $29.2(63 / 256)$ \\
\hline
\end{tabular}

${ }^{a-c}$ Different letters indicate difference between variables within columns $(P<0.05)$.

${ }^{1}$ Duration is the total time above the threshold (35 index value; from a neck-mounted accelerometer).

${ }^{2}$ Percentage (number of cows pregnant at $32 \mathrm{~d} /$ number of cows inseminated).

${ }^{3}$ Index represents standard deviations from each cow's own basal activity (by a neck-mounted accelerometer).

${ }^{4}$ Relative increase in activity was calculated as the percent increase in activity from each cow's own basal activity (by a leg-mounted pedometer).

${ }^{5}$ Secondary signs (signs of repeated mounting activity, clear vaginal mucus and uterine tonus) were classified as weak (at least 1 sign), normal (at least 2 signs), or strong (3 secondary signs).

differ $(P=0.72)$ between estrus events classified as high or low PA from both AAM. The concentration of estradiol in plasma was only weakly correlated with HT and BO PA of estrus events $(\mathrm{r}=0.02, P<0.01)$, although greater estradiol concentration was found in cows with high PA compared with low PA $(9.5 \pm 0.3$ vs. $8.2 \pm 0.2$ and $8.9 \pm 0.2$ vs. $8.1 \pm 0.2 \mathrm{ng} / \mathrm{mL}$, for HT and BO, respectively; $P<0.02$ ). Follicle diameter and concentration of estradiol in plasma were affected by parity $(P<0.01)$ and BCS $(P<0.05)$, but not by stage of lactation $(P>0.42)$. Milk production was not correlated with both follicle diameter $(\mathrm{r}=0.02$; $P=0.15)$ and estradiol concentration $(\mathrm{r}=0.02 ; P=$ $0.10)$. When milk production was divided in quartiles, follicle diameter increased with milk production $(P<$ 0.01 ), but no difference in circulating concentrations of estradiol was found $(P>0.10$

\section{Risk Factors for P/AI}

The $\mathrm{P} / \mathrm{AI}$ was not influenced by parity $(P=0.91)$, stage of lactation $(P=0.31)$, or secondary signs of estrus $(P=0.54)$. Milk production also had no effect on $\mathrm{P} / \mathrm{AI}(P=0.87)$ with only marginal numerical difference among quartiles. In contrast, cows with greater BCS had greater $\mathrm{P} / \mathrm{AI}$ than cows with lower BCS $(P$ $<0.01$; Table 1$)$. The $\mathrm{P} / \mathrm{AI}$ was not affected by preovulatory follicle diameter $(P=0.15)$, or by estradiol concentrations $(P=0.40)$.

Cows that expressed high PA had greater P/AI compared with low PA as measured by HT (37.4 vs. $23.9 \% ; P=0.004$, Figure $4 \mathrm{~A})$, as well as by BO $(33.5$ vs. $21.4 \% ; P=0.001$, Figure $4 \mathrm{~B})$. The distribution of $\mathrm{P} / \mathrm{AI}$ percentages according to increased $\mathrm{PA}$ at estrus is illustrated in Figure 5.

\section{DISCUSSION}

In the current study, some major risk factors related to PA and DU of estrus events were assessed. Even though new technologies capture physical activity using sensors and algorithms for data processing that are significantly different than those used in recent past, it was interesting to observe a lack or relatively weak correlation between measurements of estrus expression and milk production and preovulatory follicle 

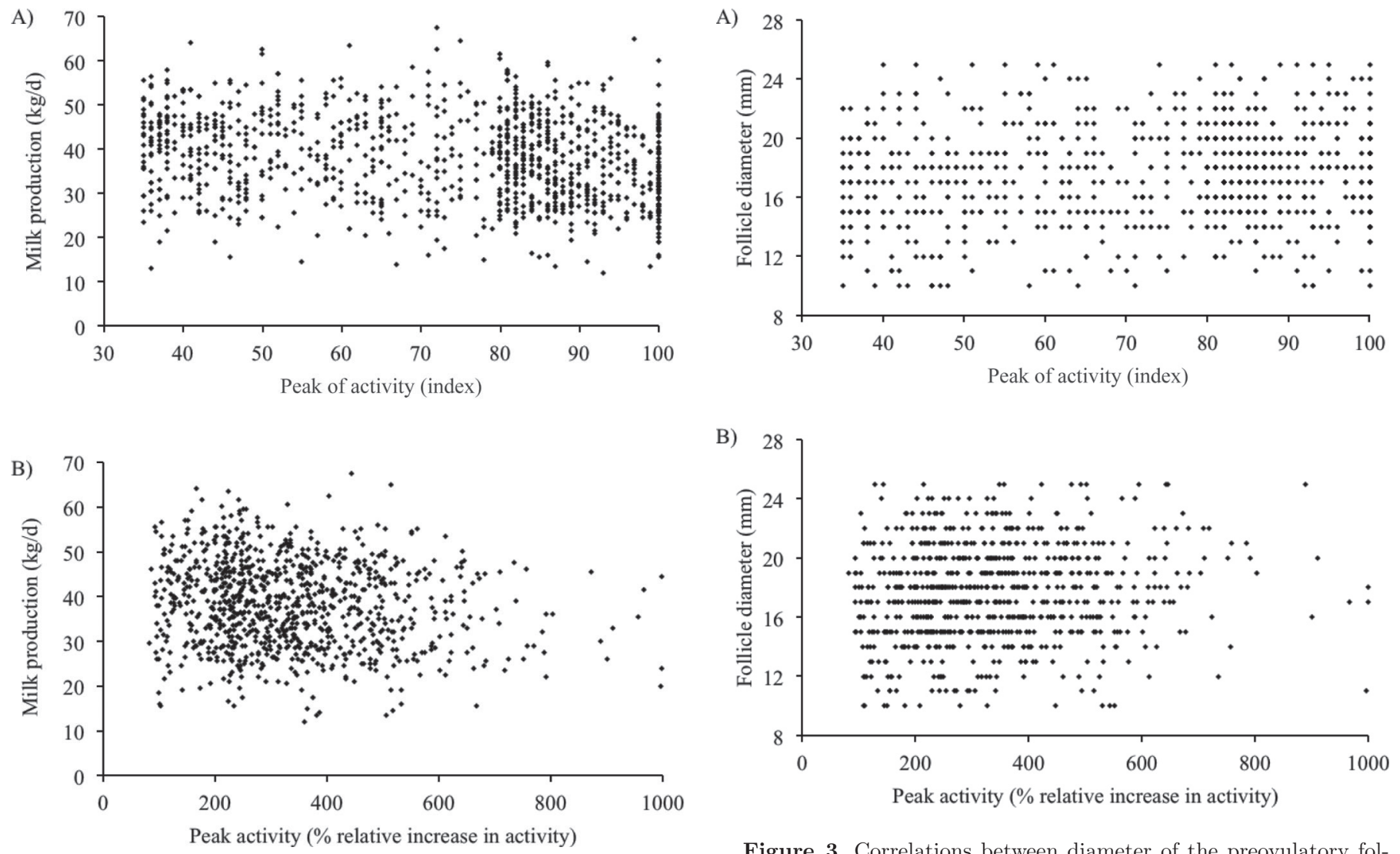

Figure 2. Correlations between milk production at the day of AI and (A) peak of activity (index value) measured by a neck-mounted accelerometer $(\mathrm{r}=0.20, P<0.01)$ and $(\mathrm{B})$ percent relative increase in activity measured by a leg-mounted pedometer $(\mathrm{r}=0.05, P<0.01)$.

diameter. Although a greater concentration of estradiol was observed in plasma from events classified as high intensity, the correlation with PA and DU was weak and was subjected to great variation. A substantial increase in P/AI from events of high PA was noted. The improvement in fertility was expected from cows with greater PA; however, it is commonly thought that highintensity estrus is associated with differences in BCS, parity, or even lactation stage and health, which in turn would affect fertility. In fact, we observed greater PA and DU as BCS increased as well as in primiparous cows, but greater $\mathrm{P} / \mathrm{AI}$ still occurred in spite of those and other risk factors known to affect conception rates. It is possible that information already available in herdmanagement software used on commercial dairy farms could be used to calibrate AAM to take into account present phenotypical conditions of the cow. The use of PA and DU measurements could assist in the prediction of fertility and improve decision making in reproductive programs using activity monitors. Moreover, there is potential to use AAM systems as an objective and ac-

Figure 3. Correlations between diameter of the preovulatory follicle and (A) peak of activity (index value) measured by a neck-mounted accelerometer $(\mathrm{r}=0.07, P=0.03)$ and $(\mathrm{B})$ percent relative increase in activity measured by a leg-mounted pedometer $(\mathrm{r}=0.01, P=0.02)$.

curate tool to select animals of superior estrus expression, although this topic still warrants further research.

Body condition score was the major factor associated with physical activity at estrus and P/AI. This study supported conclusions by Løvendahl and Chagunda (2010), who observed that in the first 5 mo after calving, low early postpartum BCS had a negative correlation with estrus activity. Further support is provided by Aungier et al. (2012), who reported that a 0.25-point increase in BCS was significantly correlated with an increase in physical activity before ovulation. Cows that lost less than $100 \mathrm{~kg}$ of $\mathrm{BW}$ from 2 wk precalving to $5 \mathrm{wk}$ postcalving had greater PA in the first 2 estrus episodes postpartum (Burnett et al., 2015). The specific mechanism by which a temporary state of negative energy balance reduces estrogen-dependent estrus behavior is unclear.

In our study, multiparous cows expressed lower PA and DU than primiparous. López-Gatius et al. (2005) found that parity was significantly associated with walking activity and reported that for each additional parity number, walking activity at an estrus episode was reduced by $21.4 \%$. On the contrary, Walker et al. 

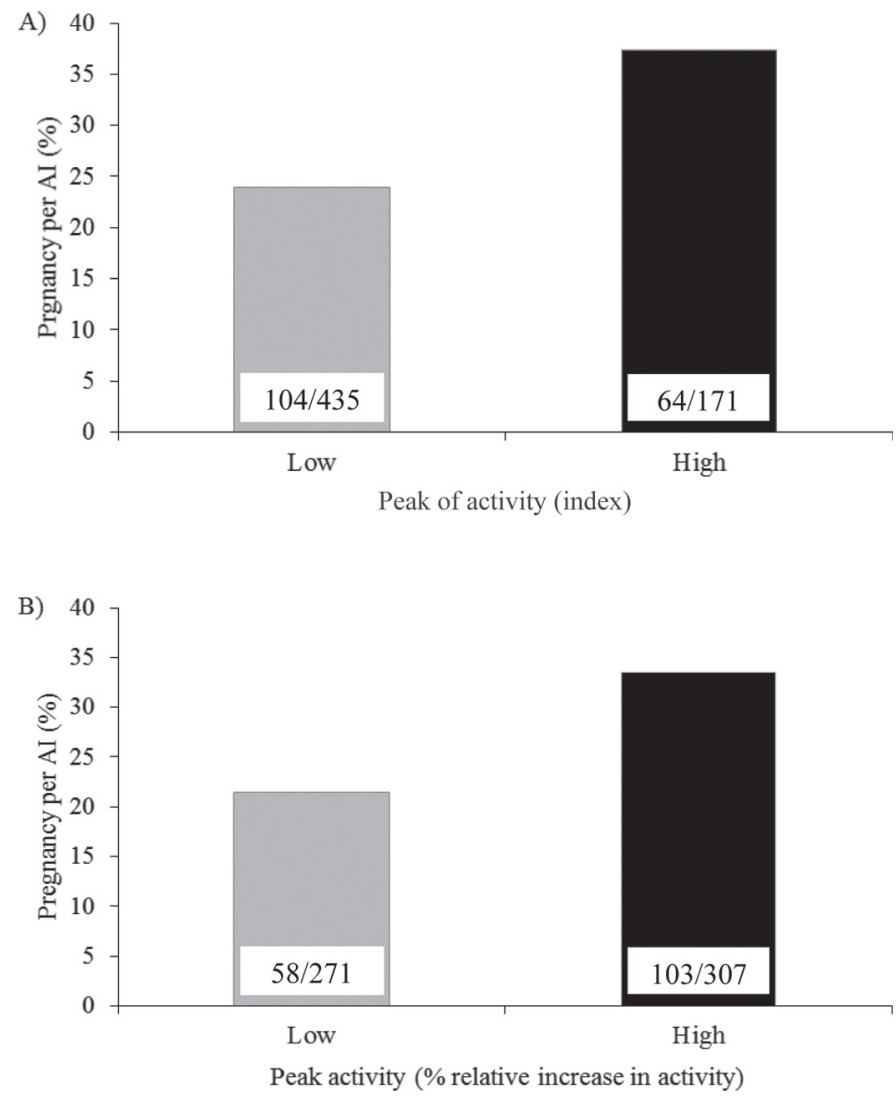

Figure 4. Pregnancy per AI (\%) according to categories of peak activity during estrus: (A) low (35 to 89 index) or high (90 to 100 index) peak activity (index) at estrus episodes detected by a neckmounted accelerometer $(P=0.004)$; and (B) low (80 to $321 \%)$ or high $(>321 \%)$ relative increase in activity (\%) at estrus episodes detected by a leg-mounted pedometer $(P=0.001)$.

(1996) described that duration of estrus was nearly $50 \%$ shorter for primiparous than for multiparous lactating dairy cows. Our study does not support findings from recent studies that reported no association between parity and physical activity at estrus (Arney et al., 1994; Veerkamp et al., 2000; Løvendahl and Chagunda 2010). Methodological differences may explain variation among different studies on the association between parity and physical activity. This study used AAM that would record activity levels every $2 \mathrm{~h}$. The AAM used by Løvendahl and Chagunda (2010) transmitted signals every hour, potentially increasing the rate of false positives. Additionally, our study employed only Holstein cattle as test subjects, whereas Løvendahl and Chagunda (2010) used 3 breeds: Jersey, Holstein, and Red Dane. Research conducted by Orihuela (2000) highlights the importance of cattle breed on the level of physical activity expressed at estrus, which can potentially be extrapolated to include parity. Two different AAM were used in the current study and the
Table 2. Means \pm SD for preovulatory follicle diameter and estradiol concentration according to milk production, lactation stage, peak of activity, parity, and BCS

\begin{tabular}{|c|c|c|}
\hline Variable & $\begin{array}{l}\text { Follicle } \\
\text { diameter } \\
(\mathrm{mm})\end{array}$ & $\begin{array}{c}\text { Estradiol } \\
\text { concentration } \\
(\mathrm{pg} / \mathrm{mL})\end{array}$ \\
\hline \multicolumn{3}{|l|}{ Milk production $(\mathrm{kg} / \mathrm{d})$} \\
\hline$\leq 31.3$ & $18.0 \pm 0.4$ & $9.2 \pm 0.3$ \\
\hline$\overline{31.4-38.8}$ & $18.4 \pm 0.4$ & $8.4 \pm 0.3$ \\
\hline $38.9-45.0$ & $19.3 \pm 0.4$ & $8.2 \pm 0.3$ \\
\hline$>45.0$ & $20.1 \pm 0.4$ & $8.3 \pm 0.3$ \\
\hline \multicolumn{3}{|l|}{ Lactation stage } \\
\hline Fresh $(\leq 45$ DIM $)$ & $19.1 \pm 0.5$ & $8.2 \pm 0.3$ \\
\hline Lactating (45-120 DIM) & $18.9 \pm 0.3$ & $8.5 \pm 0.2$ \\
\hline Late lactation (121-250 DIM) & $19.1 \pm 0.3$ & $8.1 \pm 0.2$ \\
\hline \multicolumn{3}{|l|}{ Peak of activity ${ }^{1}$} \\
\hline High & $18.9 \pm 0.2$ & $9.4 \pm 0.3^{\mathrm{a}}$ \\
\hline Low & $19.1 \pm 0.4$ & $8.2 \pm 0.1^{\mathrm{b}}$ \\
\hline \multicolumn{3}{|l|}{ Parity } \\
\hline Primiparous & $18.1 \pm 0.3^{\mathrm{a}}$ & $9.1 \pm 0.2^{\mathrm{a}}$ \\
\hline Multiparous & $19.5 \pm 0.2^{\mathrm{b}}$ & $8.2 \pm 0.1^{\mathrm{b}}$ \\
\hline \multicolumn{3}{|l|}{ BCS } \\
\hline Low $(\leq 2.5)$ & $18.4 \pm 0.4^{\mathrm{a}}$ & $7.6 \pm 0.3^{\mathrm{a}}$ \\
\hline Medium $(2.75-3.0)$ & $18.9 \pm 0.2^{\mathrm{a}}$ & $8.7 \pm 0.1^{\mathrm{b}}$ \\
\hline High $(\geq 3.25)$ & $20.4 \pm 0.6^{\mathrm{b}}$ & $8.8 \pm 0.4^{\mathrm{c}}$ \\
\hline
\end{tabular}

${ }^{a-c}$ Within the same column and subheading, different letters indicate difference at $P<0.05$.

${ }^{1}$ Peak of activity measured by a neck-mounted accelerometer: low $=35$ to 89 index, high $=90$ to 100 index.

correlation of PA of estrus episodes was only moderate between the systems. It seems that different AAM systems have different methods of calculating physical movement, consequently influencing measurements of baseline levels and relative increases in activity during estrus.

Greater milk production has been negatively correlated with standing to be mounted at estrus (López et al., 2004; Rivera et al., 2010). The decrease in concentrations of estradiol possibly caused by increased hepatic blood flow and steroid clearance (Sangsritavong et al., 2002; Vasconcelos et al., 2003) is a possible cause for the decreased estrus-related behavior, most notably standing to be mounted. Our study also found greater PA and DU only for animals in the lowest quartile of milk production, but not among the other milk production categories. We could assume that the data partially agree with previous research (López et al., 2004; Rivera et al., 2010); however, it seems that mounting activity is more affected than overall physical activity measured by AAM systems. Recent studies from our group (Madureira et al., 2015; Silper et al., 2015) found that heifers and cows with lower baseline levels of activity tend to have greater relative increase in PA, but not necessarily greater absolute increases in step counts during estrus. In spite of the results from the current study, PA during estrus was still weakly associated with milk production, emphasizing the influence of other 
A)

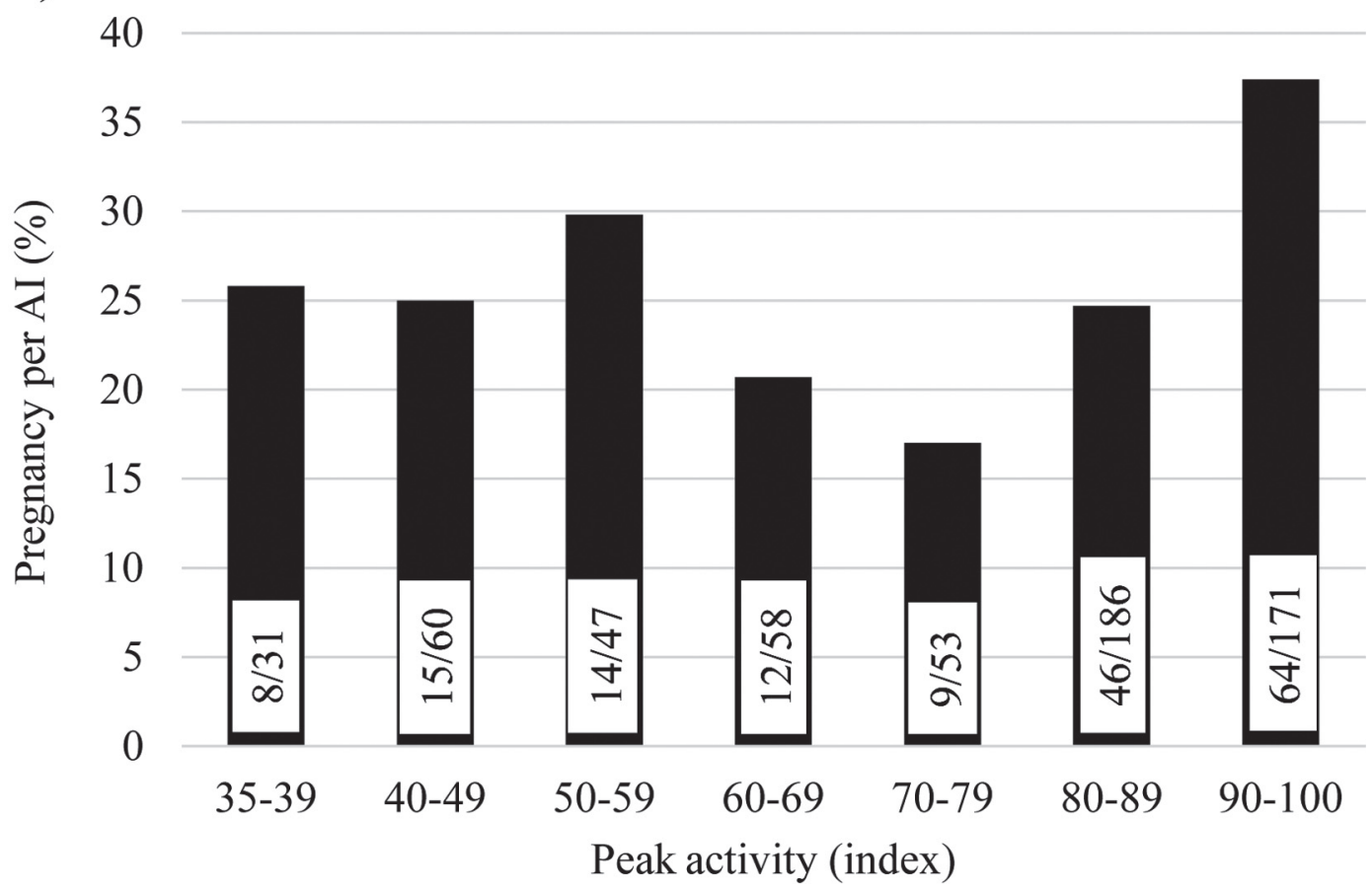

B)

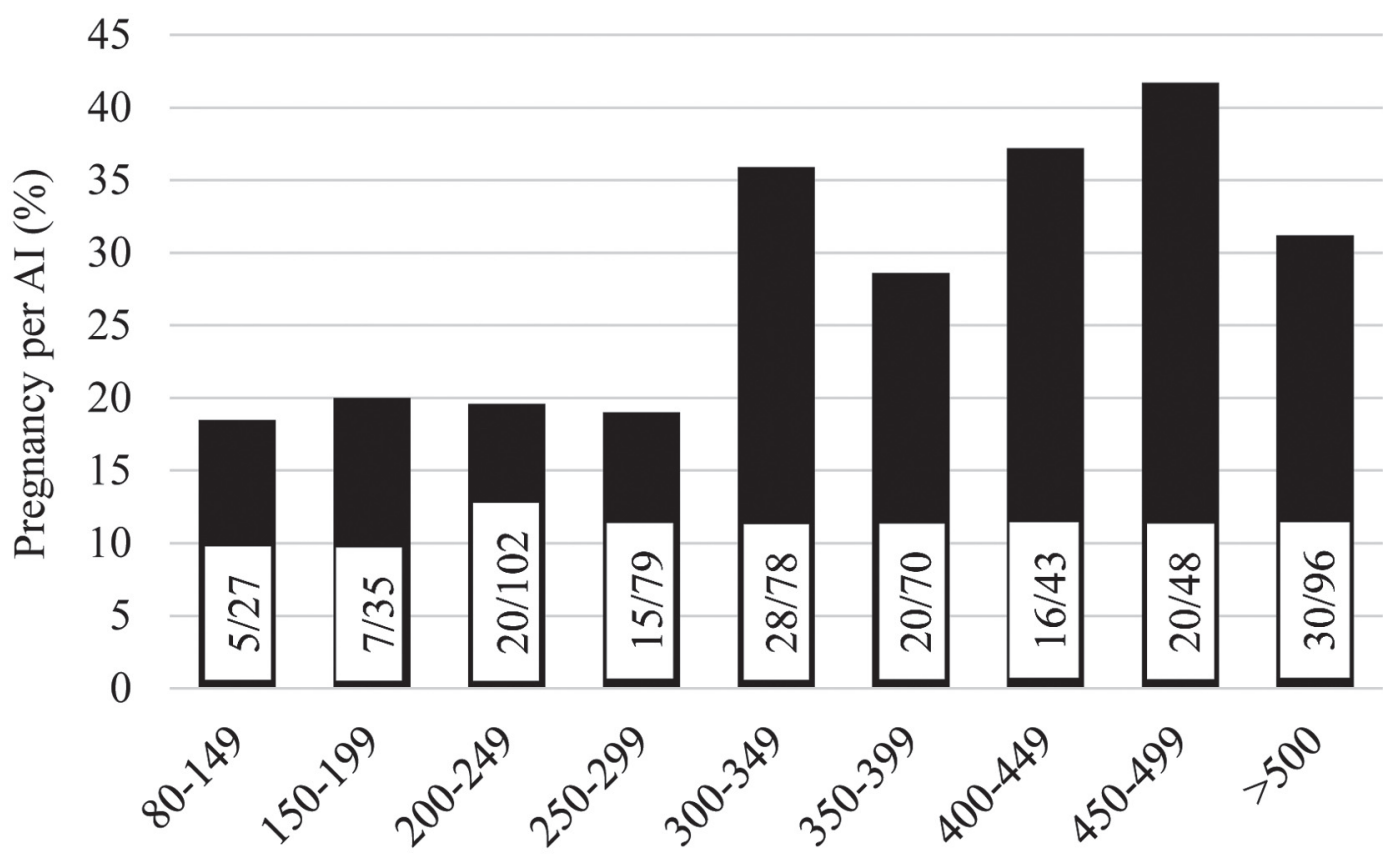

Peak activity (\% relative increase in activity)

Figure 5. Distribution of pregnancy per AI (\%) according to peak activity during estrus detected by (A) a neck-mounted accelerometer and (B) a leg-mounted pedometer. 
factors, such as BCS and parity, and probably other factors such as group size, health status, and lameness (Van Vliet and Van Eerdenburg, 1996; López-Gatius et al., 2005; Morris et al., 2009).

In our study, we found that the HT system had a PPV of $89.6 \%$, whereas the BO system had a PPV of $85.5 \%$. The true episodes were verified from ovarian structures and are in agreement with recent studies reporting 72 (Aungier et al., 2012) and 90\% (Aungier et al., 2015) PPV of estrous detection using the same technology (HT). At-Taras and Spahr (2001) found a similar PPV for a pedometer system. Collectively, the current AAM systems detect a low percentage of false positives, but accurate calculation of sensitivity is still a field for future studies.

The correlation between the preovulatory follicle diameter and plasma estradiol was weak $(\mathrm{r}=0.17)$ and is in agreement with values reported elsewhere (Glencross and Pope, 1981; Cook et al., 1986; Sartori et al., 2004; Walker et al., 2008). Although reports have found that a larger follicle is associated with greater concentrations of estradiol in plasma (Cerri et al., 2004), it is clear from the current experiment that parity, BCS, and, ultimately, milk production are the factors with the greatest effect on circulating concentrations of estradiol. Cows classified as high activity had similar preovulatory follicle diameter, but greater concentrations of estradiol in plasma than cows classified as low. In spite of the differences in estradiol concentrations found when cows were divided in categories by estrus activity, the PA measured by both AAM systems was only weakly correlated with concentration of estradiol in plasma. A recent study by Aungier et al. (2015) observed no correlation between activity clusters measured by AAM and FSH, LH, and estradiol profiles. However, a greater peak concentration of estradiol in plasma was in fact associated with standing and estrusrelated behaviors. The expression of estrus behavior is triggered by high concentrations of estradiol-17 $\beta$ produced by the preovulatory follicle (Allrich, 1994; Forde et al., 2011). It is reasonable to assume based on this and other studies (Walker et al., 2008; Aungier et al., 2015 ) that some level of dependence exists between PA at estrus and estradiol concentrations in plasma, but the influence of other risk factors is probably greater than previously thought. One factor that has not been addressed in this or previous studies is the effect that sampling at random times of the day may have on estradiol concentrations, considering the acute changes in ovarian steroid concentrations observed in postprandial periods (Vasconcelos et al., 2003). In addition, in spite of the efforts to draw a blood sample early in the estrus, it was impossible to determine when the sample was collected in relation to the LH surge and a possible negative effect on estradiol concentrations in plasma. The degree of variation found in the current study related to ovarian dynamics, PA and DU of naturally occurring estrus, and further responses in $\mathrm{P} /$ $\mathrm{AI}$ is surprising nonetheless. Interestingly, Cummins et al. (2012) found that cows classified with a greater genetic merit for fertility had pronounced effects on corpus luteum development, progesterone concentration, preovulatory follicle diameter, and behavioral estrus. More detailed studies should be conducted to approach possible management, physiological, or perhaps genetic explanations for the observed endocrine and behavioral variation and at times paradoxical correlations.

The PA during estrus was highly correlated with DU and is probably an acceptable measure of the intensity of the estrus episode. It was interesting to observe such an effect of PA (high vs. low) from both systems on $\mathrm{P} / \mathrm{AI}$. Among all risk factors included in the model of the analysis of $\mathrm{P} / \mathrm{AI}$, only $\mathrm{BCS}$ and $\mathrm{PA}$ at estrus were significant and remained in the final statistical model. Cows with high PA had approximately 12 percentage units greater P/AI than cows with low PA, which represents $35 \%$ improvement in fertility. Previously, López-Gatius et al. (2005) reported an improvement of 1.001-fold for every unit of relative increase in walking activity. In another recent study (Madureira et al., 2015) using a different pedometer system and using only episodes from first AI postpartum, an even greater difference was observed (42.9 vs. $28.9 \%)$ between cows displaying high and low PA at estrus. It was previously mentioned that preovulatory follicle diameter was not different between PA categories, but that does not imply that proestrus or dominance length was similar, as no control of follicular emergence was present in the current study. Therefore, proestrus and dominance length (Bleach et al., 2004; Cerri et al., 2009) cannot be ruled out as possible causes related to the reduced fertility observed. Increased length of proestrus (Ribeiro et al., 2012) and display of estrus at AI (Pereira et al., 2013) are associated with a reduction in pregnancy losses. Furthermore, Pereira et al. (2014) reported that animals that display estrus at AI had decreased pregnancy losses regardless of the diameter of the preovulatory follicle. Peak concentration of estradiol at estrus was different between high and low PA estrus episodes (approximately $1 \mathrm{pg} / \mathrm{mL}$ ) to a similar degree found between the low- versus highmilk production groups, high- versus low-BCS groups, and primiparous versus multiparous groups, which is probably sufficient to at least partly explain changes in fertility. When estradiol cypionate was used to induce estrus and ovulation, therefore bringing circulating 
concentrations of estradiol to high concentrations, the PA measured by a pedometer system still significantly affected P/AI results (Madureira et al., 2015).

The ovulation of preovulatory follicles with similar diameter would suggest little change in concentrations of progesterone after AI. This information was not collected in the present study, but data from Madureira et al. (2015) suggests that concentrations of progesterone $10 \mathrm{~d}$ after AI was greater in cows displaying highintensity estrus at AI. The faster increase in progesterone early in the cycle could result in increased early embryonic development (Mann and Lamming, 2001; Bisinotto et al., 2010a), possibly due to changes in the endometrium receptor profile (Lonergan, 2011), and therefore a reason for increased P/AI found in animals with high PA in our study.

Another possible factor influencing $\mathrm{P} / \mathrm{AI}$ is the ovulation rate from cows with different PA at estrus. Madureira et al. (2015) observed a greater failure of ovulation rate of cows that displayed estrus with a relative increase in PA from 80 to $100 \%$, the lowest relative increase possible after crossing the threshold from the AAM used. Whereas this observation is certainly important to explain our observations, it is limited to cows expressing very low PA during estrus as the threshold dividing high and low PA categories was over $300 \%$ relative increase in the current study. A potential explanation to correlate $\mathrm{PA}$ and $\mathrm{P} / \mathrm{AI}$ that has not been extensively studied is that cows could have greater than expected individual variations in their ability to express estrogen receptors in the endometrium and, perhaps more importantly, in the hypothalamus. This would, in turn, generate cows that are more likely to translate circulating concentrations of estradiol into estrus-related behaviors, and later into a more adequate uterine environment for embryo development.

\section{CONCLUSIONS}

In conclusion, measurements of estrus events captured by AAM are correlated with BCS, parity, and secondary behavior signs related to estrus. Estrus intensity and duration were only weakly correlated with milk production, preovulatory follicle diameter, and concentration of estradiol at estrus. Cows that had estrus of high intensity were significantly more fertile than those with low-intensity estrus. Both HT and BO automated activity monitor had high PPV for the detection of estrus events. More importantly, quantitative information from AAM systems could be intensively used to improve estrous detection quality, predict P/ AI outcomes, improve decision-making in reproductive programs using AAM, and potentially be used as a tool to select animals of superior estrous expression.

\section{ACKNOWLEDGMENTS}

This study was supported by a contribution from the Dairy Research Cluster Initiative [Dairy Farmers of Canada (Ottawa, ON), Agriculture and Agri-Food Canada (Ottawa, ON), the Canadian Dairy Network (Guelph, ON) and the Canadian Dairy Commission (Ottawa, ON)], the Natural Sciences and Engineering Research Council of Canada (Ottawa, ON), and Westgen (Milner, BC)]. A. M. L. Madureira was funded by $\mathrm{CNPq}$ (Conselho Nacional de Desenvolvimento Tecnológico, Brasília, Brazil). The authors also thank UBC students M. M. Reis, C. Ramos, Z. J. Cocker, J. Luu, and farm staff who assisted with the data collection at the UBC Dairy Education and Research Centre.

\section{REFERENCES}

Allison, P. D. 1999. Logistic Regression Using the SAS System: Theory and Application. SAS Inst. Inc., Cary, NC.

Allrich, R. D. 1994. Endocrine and neural control of estrus in dairy cows. J. Dairy Sci. 77:2738-2744.

Arney, D., S. E. Kitwood, and C. J. C. Phillips. 1994. The increase in activity during oestrus in dairy cows. Appl. Anim. Behav. Sci. 40:211-218.

At-Taras, E. E., and S. L. Spahr. 2001. Detection and characterization of estrus in dairy cattle with an electronic heatmount detector and an electronic activity tag. J. Dairy Sci. 84:792-798.

Aungier, S. P. M., J. F. Roche, P. Duffy, S. Scully, and M. A. Crowe. 2015. The relationship between activity clusters detected by an automatic activity monitor and endocrine changes during the periestrus period in lactating dairy cows. J. Dairy Sci. 98:1666-1684.

Aungier, S. P. M., J. F. Roche, M. Sheehy, and M. A. Crowe. 2012 Effects of management and health on the use of activity monitoring for estrus detection in dairy cows. J. Dairy Sci. 95:2452-2466.

Bisinotto, R. S., E. S. Ribeiro, L. T. Martins, R. S. Marsola, L. F. Greco, M. G. Favoreto, C. A. Risco, W. W. Thatcher, and J. E. Santos. 2010a. Effect of interval between induction of ovulation and artificial insemination (AI) and supplemental progesterone for resynchronization on fertility of dairy cows subjected to a 5 -d timed AI program. J. Dairy Sci. 93:5798-5808.

Bleach, E. C., R. G. Glencross, and P. G. Knight. 2004. Association between ovarian follicle development and pregnancy rates in dairy cows undergoing spontaneous oestrous cycles. Reproduction 127:621-629.

Burke, C. R., M. L. Mussard, C. L. Gasser, D. E. Grum, and M. L. Day. 2003. Estradiol benzoate delays new follicular wave emergence in a dose-dependent manner after ablation of the dominant ovarian follicle in cattle. Theriogenology 60:647-658.

Burnett, T. A., M. A. Khan, M. A. G. von Keyserlingk, and R. L. A Cerri. 2015. Body weight loss of cows early postpartum has negative effects on estrous expression. J. Dairy Sci. 98(Suppl. 2):90. (Abstr.).

Canadian Council on Animal Care (CCAC). 2009. CCAC Guidelines On: The Care and Use of Farm Animals in Research, Teaching And Testing. CCAC, Ottawa, ON, Canada.

Cerri, R. L., H. M. Rutigliano, R. C. Chebel, and J. E. P. Santos. 2009. Period of dominance of the ovulatory follicle influences embryo quality in lactating dairy cows. Reproduction 137:813-823.

Cerri, R. L., J. E. Santos, S. O. Juchem, K. N. Galvao, and R. C. Chebel. 2004. Timed artificial insemination with estradiol cypionate or insemination at estrus in high-producing dairy cows. J. Dairy Sci. 87:3704-3715.

Cook, D. L., T. A. Winters, L. A. Horstman, and R. D. Allrich. 1986. Induction of estrus in ovariectomized cows and heifers: Effects of 
estradiol benzoate and gonadotropin releasing hormone. J. Anim. Sci. 63:546-550.

Cummins, S. B., P. Lonergan, A. C. Evans, and S. T. Butler. 2012. Genetic merit for fertility traits in Holstein cows: II. Ovarian follicular and corpus luteum dynamics, reproductive hormones, and estrus behavior. J. Dairy Sci. 95:3698-3710.

Edmonson, A. J., I. J. Lean, L. D. Weaver, T. Farver, and G. Webster. 1989. A body condition score chart for Holstein dairy cows. J Dairy Sci. 72:68-78.

Forde, N., M. E. Beltman, G. B. Duffy, P. Duffy, J. P. Mehta, P. O'Gaora, J. F. Roche, P. Lonergan, and M. A. Crowe. 2011. Changes in the endometrial transcriptome during the bovine estrous cycle: Effect of low circulating progesterone and consequences for conceptus elongation. Biol. Reprod. 84:266-278.

Glencross, R. G., and G. S. Pope. 1981. Concentrations of oestradiol$17 \beta$ and progesterone in the plasma of dairy heifers before and after cloprostenol-induced and natural luteolysis and during early pregnancy. Anim. Reprod. Sci. 4:93-106.

Holman, A., J. Thompson, J. E. Routly, J. Cameron, D. N. Jones, D. Grove-White, R. F. Smith, and H. Dobson. 2011. Comparison of oetrus detection methods in dairy cattle. Vet. Rec. 169:47.

Jónsson, R., M. Blanke, N. K. Poulsen, F. Caponetti, and S. Højsgaard. 2011. Oestrus detection in dairy cows from activity and lying data using on-line individual models. Comput. Electron. Agric. 76:6-15.

Lonergan, P. 2011. Influence of progesterone on oocyte quality and embryo development in cows. Theriogenology 76:1594-1601.

López, H., Z. Wu, L. D. Satter, and M. C. Wiltbank. 2004. Effect of dietary phosphorus concentration on estrous behaviour of lactating dairy cows. Theriogenology 61:437-445.

López-Gatius, F., P. Santolaria, I. Mundet, and J. L. Yániz. 2005. Walking activity at estrus and subsequent fertility in dairy cows. Theriogenology 63:1419-1429.

Løvendahl, P., and G. G. Chagunda. 2010. On the use of physical activity monitoring for estrus detection in dairy cows. J. Dairy Sci. 93:249-259.

Lyimo, Z. C., M. Nielen, W. Ouweltjes, T. A. Kruip, and F. J. van Eerdenburg. 2000. Relationship among estradiol, cortisol and intensity of estrous behavior in dairy cattle. Theriogenology 53:17831795 .

Madureira, A. M. L., B. F. Silper, L. B. Polsky, T. A. Burnette, E. L. Drago Filho, S. Soriano, A. F. Sica, J. L. M. Vasconcelos, and R. L. A. Cerri. 2015. Effects of expression of estrus measured by activity monitors on ovarian dynamics and conception risk in Holstein cows. J. Dairy Sci. 98(Suppl. 2):874. (Abstr.)

Mann, G. E., and G. E. Lamming. 2001. Relationship between maternal endocrine environment, early embryo development and inhibition of the luteolytic mechanism in cows. Reproduction 121:175-180

Morris, M. J., S. L. Walker, D. N. Jones, J. E. Routly, R. F. Smith, and H. Dobson. 2009. Influence of somatic cell count, body condition and lameness on follicular growth and ovulation in dairy cows. Theriogenology 71:801-806.

NRC. 2001. Nutrient Requirements for Dairy Cattle. Natl. Acad. Sci., Washington, DC

Orihuela, A. 2000. Some factors affecting the behavioural manifestation of oestrus in cattle: A review. Appl. Anim. Behav. Sci. 70:1-16.
Pereira, M. H. C., A. D. P. Rodrigues, R. J. De Carvalho, M. C. Wiltbank, and J. L. M. Vasconcelos. 2014. Increasing length of an estradiol and progesterone timed artificial insemination protocol decreases pregnancy losses in lactating dairy cows. J. Dairy Sci. 97:1454-1464.

Pereira, M. H. C., A. D. P. Rodrigues, T. Martins, W. V. C. Oliveira, P. S. A. Silveira, M. C. Wiltbank, and J. L. M. Vasconcelos. 2013. Timed artificial insemination programs during summer in lactating dairy cows: Comparison of the 5-d Cosynch protocol with an estrogen/progesterone-based protocol. J. Dairy Sci. 96:6904-6914.

Ribeiro, E. S., A. P. Monteiro, F. S. Lima, H. Ayres, R. S. Bisinotto, M. Favoreto, L. F. Greco, R. S. Marsola, W. W. Thatcher, and J. E. P. Santos. 2012. Effects of presynchronization and length of proestrus on fertility of grazing dairy cows subjected to a 5-day timed artificial insemination protocol. J. Dairy Sci. 95:2513-2522.

Rivera, F., C. Narciso, R. Oliveira, R. L. A. Cerri, A. Correa-Calderón, R. C. Chebel, and J. E. P. Santos. 2010. Effect of bovine somatotropin $(500 \mathrm{mg})$ administered at ten-day intervals on ovulatory responses, expression of estrus, and fertility in dairy cows. J. Dairy Sci. 93:1500-1510.

Roelofs, J., F. López-Gatius, R. H. F. Hunter, F. J. C. M. van Eerdenburg, and C. Hanzen. 2010. When is a cow in estrus? Clinical and practical aspects. Theriogenology 74:327-344. http://dx.doi. org $/ 10.1016 / j$. theriogenology.2010.02.016.

Sangsritavong, S., D. K. Combs, R. Sartori, and M. C. Wiltbank. 2002 High feed intake increases blood flow and metabolism of progesterone and estradiol-173 in dairy cattle. J. Dairy Sci. 85:2831-2842.

Sartori, R., J. M. Haughian, R. D. Shaver, G. J. M. Rosa, and M. C. Wiltbank. 2004. Comparison of ovarian function and circulating steroids in estrous cycles of Holstein heifers and lactating cows. J. Dairy Sci. 87:905-920. http://dx.doi.org/10.3168/jds.S00220302(04)73235-X.

Silper, B. F., I. Robles, A. M. L. Madureira, T. A. Burnett, M. M. Reis, A. M. de Passillé, J. Rushen, and R. L. A. Cerri. 2015. Automated and visual measurements of estrous behavior and their sources of variation in Holstein heifers I: Walking activity and behavior frequency. Theriogenology 84:312-320.

Van Eerdenburg, F. J. C. M., D. Karthaus, M. A. M. Taverne, I. Merics, and O. Szenci. 2002. The relationship between estrous behavioural score and time of ovulation in dairy cattle. J. Dairy Sci $85: 1150-1156$.

Van Vliet, J. H., and F. J. C. M. Van Eerdenburg. 1996. Sexual activies and oestrus detection in lactating Holstein cows. Appl. Anim. Behav. Sci. 50:57-69.

Vasconcelos, J. L. M., S. Sangsritavong, S. J. Tsai, and M. C. Wiltbank. 2003. Acute reduction in serum progesterone concentrations after feed intake in dairy cows. Theriogenology 60:795-807.

Veerkamp, R. F., J. K. Oldenbroek, H. J. van der Gaast, and J. H. J. van der Werf. 2000. Genetic correlation between days until start of luteal activity and milk yield, energy balance, and live weights. J. Dairy Sci. 83:577-583.

Walker, S. L., R. F. Smith, D. N. Jones, J. E. Routley, and H. Dobson. 2008. Chronic stress, hormone profiles and estrus intensity in dairy cattle. Horm. Behav. 53:493-501.

Walker, W. L., R. L. Nebel, and M. L. McGilliard. 1996. Time of ovulation relative to mounting activity in dairy cattle. J. Dairy Sci. 79:1555-1561. 